type buildings is advocated, and the following facts, together with others, based largely on the experience gained in regions subject to severe earthquakes, should be taken into account when permanent rebuilding at Accra is being considered:

(a) A building should be of simple design and should be so constructed that it will move as a whole in an earthquake.

(b) Buildings should be as nearly square and as low as is conveniently possible.

(c) Foundations should be strong and deep.

(d) All unnecessary ornamental work should be avoided.

(e) Walls should be light and strong. Arches and windows are a source of weakness.

(f) Roofs should be light and rigid and should not be steeply inclined. (g) Piers may be a great source of weakness. Arched piers should not be used, and all piers should be constructed to withstand an acceleration of at least $3 \mathrm{ft}$. per second from any direction; in other words, the width at the base of the pier should be at least one tenth of the height of the pier. Tapered piers are advisable in seismic areas and stronger cement may be used near the base of a pier.

(h) Well-constructed wooden buildings will oscillate greatly but will withstand anything but very severe earthquakes unless the structures are built on unconsolidated materials.

(i) Good-quality building materials and workmanship are essential.

(j) Inferior-quality buildings should not be of more than one story.

\title{
RECENT RESEARCHES ON RUBBER
}

\section{RUBBER FRACTIONS}

$\mathrm{P}$ UBLICATIONS Nos. 3-6 of the British Rubber Producers' Research Association follow a wellbeaten track with interesting new details. On the general principle that rubber is a mixture of molecules of different lengths, several previous investigations have attempted to sort the molecules out either by fractional precipitation from solution or by fractional dissolution. A division into 'sol' and 'gel' rubber on these lines has become more or less standard. G. F. Bloomfield and E. H. Farmer (Inst. Rubber Ind. Trans., 16, 69 ; 1940) have adopted fractional extraction as their mode of approach, using mixtures of petroleum ether and acetone as extractant, differentiating the fractions in relation to the increasing proportion of petrol in the extracting mixture. Oxygen was rigidly excluded at all stages, but it may have been unfortunate to add $\beta$-phenylnaphthylamine to the extraction mass; this compound is an anti-oxidant for vulcanized rubber, but may act in some conditions as an oxidation promoter for raw rubber.

Four distinctive fractions were taken at arbitrary points-a first small one containing appreciable combined oxygen; a second fraction comprising a pure hydrocarbon of relatively low molecular weight ; a third, also pure hydrocarbon, of higher molecular weight; and a fourth containing appreciable combined nitrogen. There was also an insoluble residue. Different types of raw rubber gave different proportions of extract, and at various compositions of the mixed solvent, so that there is little that can be said of a conclusive nature about the make-up of rubber in relation to this extractant.

However, G. Gee and L. R. G. Treloar (Inst. Rubber Ind. Trans., 16, $184 ;$ 1940) have examined several properties of some of these fractions with results of considerable interest. Using methods previously described (Gee, Trans. Fraraday Soc., 36, $1162,1171 ; 1940)$, the molecular weights of the four fractions, in a particular case and from viscosity data, were found as $63,000,240,000,350,000$ and 360,000 . Experimental technique is not yet available to decide whether these, or some of them, represent well-defined classes of uniform length molecules, or merely average 'cuts' in a continuous range of molecular lengths. Several of the properties measured varied in a systematic way with the molecular weight, as for example, the plastic flow, tensile behaviour, crystallization phenomena, and extensibility range. Properties independent of molecular weight seem to be the temperature at which retraction occurs after extension to produce crystallization, and the low-temperature elastic limit. It is particularly interesting to observe that the physical properties of the third fraction are remarkably similar to those of normal crêpe rubber, indicating clearly that the usual elastic properties of (raw) rubber are not dependent on the presence of either low-molecular constituents or 'gel-skeletons'.

\section{Proteins in Hevea Latex}

Publication No. 2 of the British Rubber Producers' Research Association brings out a marked resemblance between rubber latex protein and typical leaf proteins. The following table, from G. R. Tristram (Biochem $J ., 34,301$; 1940), compares his analyses with leaf protein analyses by Chibnall:

\begin{tabular}{|l|c|c|}
\hline \multicolumn{2}{|c|}{$\begin{array}{c}\text { Amino-acids } \\
\text { Latex }\end{array}$} & $\begin{array}{c}\text { percentage protein } \\
\text { Various leaves }\end{array}$ \\
\hline Ammonia & $1 \cdot 46$ & $0 \cdot 97-1 \cdot 17$ \\
Arginine & $6 \cdot 90$ & $7 \cdot 1-8 \cdot 2$ \\
Lysine & $5 \cdot 68$ & $4 \cdot 6-6 \cdot 2$ \\
Histidine & $0 \cdot 63$ & $1 \cdot 0-1 \cdot 6$ \\
Glutamic acid & $13 \cdot 68$ & $11 \cdot 4-14 \cdot 0$ \\
Aspartic acid & $10 \cdot 5$ & $7 \cdot 9-8 \cdot 8$ \\
Tyrosine & $7 \cdot 24$ & $4 \cdot 8-6 \cdot 1$ \\
Tryptophan & $1 \cdot 49$ & $2 \cdot 1-2 \cdot 4$ \\
Methionine & $1 \cdot 12$ & $2 \cdot 2-2 \cdot 7$ \\
Cystine & $1 \cdot 02$ & $1 \cdot 4-2 \cdot 2$ \\
\hline \multicolumn{1}{|c}{$\%$ Total nitrogen } & $14 \cdot 95$ & $12 \cdot 8-15 \cdot 0$ \\
\hline
\end{tabular}

The similarity in the two sets of figures undoubtedly suggests some relationship between the proteins in the leaves and latex of Hevea brasiliensis, and the question is being pursued by way of analyses of proteins from Hevea leaves themselves.

J. McGavack and C. E. Rhines (Ind. Eng. Chem., 32, 1072 ; 1940) recently showed that the nitrogen content of "whole latex" is approximately constant at 0.25 per cent, the anaiyses being of 117 samples, collected in a single month (thus avoiding seasonal 
variation) from many types of tree. There is a suggestion in this constancy that the tree produces some nitrogenous compound to an optimum concentration, either as an auxiliary to the synthesis of caoutchouc or as a side product of that synthesis.
Tristram's results thus throw an interesting light on such a suggestion, indicating the place of these reactions as in the Hevea leaves, a natural site for photosynthetic transformations. Further results in this field will be awaited with impatience.

\section{THE 200-IN.}

$\mathrm{T}$ HE twelfth Thomas Young Oration was delivered before a meeting of the Physical Society by Dr. H. Spencer Jones, Astronomer Royal, on May 30. He described some features of the 200-in. telescope now being constructed for the California Institute of Technology.

This telescope was made possible by a grant of six million dollars from the Rockefeller General Education Board. The design and construction of a telescope of double the aperture of the largest telescope previously built required careful considera. tion of a large number of problems. The primary problem was the construction of a 200 -in. mirror. If made, in accordance with previous practice, of a solid block of plate glass, annealing for nine years would have been required. Mirrors of stainless steel or of metal coated with glass of the same coefficient of expansion were considered but were regarded as too experimental ; fused quartz with a surface coating of clear quartz was tried but abandoned, not because the difficulties were insuperable but because the cost would have been too great. A special pyrex glass of high silica content, with a coefficient of expansion only three times that of quartz, was finally decided upon. The disk was cast, by a special technique evolved after much experimental work by the Corning Glass Company, with a ribbed honeycomb structure at the back to reduce the weight without sacrifice of rigidity. Annealing for ten months proved to be adequate for this special glass. The disk weighs $14 \frac{1}{2}$ tons and its optical figuring is well advanced.

The mounting embodies many new features. It is of a modified yoke type, the upper bearing being in the form of a giant horseshoe, $46 \mathrm{ft}$. in diameter, within the throat of which the telescope can lie for observations at the north pole of the sky. Only one machine in the world was large enough to machine this bearing. The yoke arms are hollow cylinders,

\section{TELESCOPE}

$10 \mathrm{ft}$. in diameter, joined by a bent box girder $46 \mathrm{ft}$ long, which carries the hemispherical thrust bearing, $7 \mathrm{ft}$. in diameter. An oil pad flotation system enables the $\$ 50$ tons of the moving parts to be turned with a torque of only $50 \mathrm{lb} . \mathrm{ft}$. The primary focus is at $f / 3 \cdot 3$ and the observer makes his observations within a 6-ft. diameter cylinder, supported from the upper cage of the tube. The Cassegrain focus is at $f / 16$ and observations can be made either at a focus just below the central hole of the 200 -in. mirror, where there is a platform for the observer, or, by the interposition of a diagonal flat mirror, within either of the hollow yoke arms. The Coude focus is at $f / 30$, and observations with high dispersion spectrographs can be made within a constant-temperature room just south of the telescope. At the primary focus, coma would be serious at a small angular distance from the axis; two special correcting lenses of zero power have been designed to eliminate coma. For observations of faint objects, with low-dispersion spectrographs, two special short-focus camera objectives of great relative aperture have been constructed; one of these, with relative aperture of $f / 0.35$, on the principle of the oil-immersion microscope objective, is of British design and construction. The ingenious image-slicer, designed by Dr. Bowen, will give a greatly increased efficiency in all spectrographic observations.

All auxiliary mirrors are permanently carried on the mounting and can be operated by remote control. The telescope drive is of an elaborate nature; the effects of changing refraction, of differential flexure and of errors in the gears are automatically allowed for by a system of 'computers'. A quartz-crystal oscillator provides the fundamental control of the rate of drive. A complicated system of Selsyn or interlock motors enables the telescope to be set rapidly to any predetermined position, the position of the dome and of the windscreen being automatically adjusted.

\section{WIRED RADIO BROADCASTING}

$\mathrm{W}$ IRED broadcasting has already appeared in service in Europe and other parts of the world. An article written by N. Shinohara and Y. Hirano, of the Ministry of Communications, Tokyo, in the January issue of the Nippon Electrical Communication Journal, a summary form in English of the journal of the Institute of Electrical Communication Engineers of Japan, discusses the subject, stress being laid on experiments and the basis of network design.

In one method, a wireless radio receiving and wired radio transmitting station is located at a position near a crowded area of listeners or in a suburban district, where there is little electrical disturbance. The programme received at this station is converted to audio-frequency and sent over special lines to the listeners. This method is known in Japan as an ordinary form of common broadcast reception. The pro. gramme is distributed at a fairly high level of volume, so that it is only necessary for the listener to instal a loudspeaker. The resulting low cost of the receiving apparatus is an advantage. The disadvantages, however, accompanying radio-broadcasting cannot be avoided, because this method has an intermediate wireless system. Also a large expenditure of money and materials is needed for the installation of special lines to listeners.

A second method makes use of telephone lines, to which the broadcast programme is supplied at audio-frequency. While this method greatly 